\title{
The Effect of Pressure on the Synthesis of Graphene Layers in the Flame
}

\author{
N. G. Prikhodko*, M. Auyelkhankyzy, B. T. Lesbayev, Z. A. Mansurov \\ The Institute of Combustion Problems, Almaty, Kazakhstan \\ Email: "nik99951@mail.ru
}

Received October 2013

\begin{abstract}
The results of the study of the formation of graphene layers in the flame in premixed flame propane or butane-oxygen mixture on a nickel substrate at atmospheric pressure and low pressure are given. The influence of the ratio $\mathrm{C} / \mathrm{O}$ and supply quantity of argon on the formation of graphene layers were researched. It is shown that in the flame of propane and butane on a nickel substrate is observed under these conditions the formation of predominantly 3 - 10 layers of graphene.
\end{abstract}

\section{KEYWORDS}

Graphene; Propane; Butane; Flame; Substrate; Pressure

\section{Introduction}

Graphene has extremely useful properties: extremely high carrier mobility, high electrical and thermal conductivity, the dependence of electronic properties on the presence on the surface of graphene added radicals of different nature, and others [1,2]. Application of graphene due to its unusual properties may run as a basis for new nanomaterials with improved mechanical, electrical and thermal characteristics, as well as an element of nanoelectronic devices. Graphene layers prepared by different methods: mechanical splitting of the graphite layers, graphite bundle liquid phase oxidation of graphite etc. [1-3]. A promising method of producing graphene layers is the method of synthesis of graphene in flames. The studies $[4,5]$ confirm that the process of obtaining a flame graphene can not compete with a number of existing methods. The process of formation of graphene in a flame is continuous, rapid, and inexpensive.

This paper presents the results on the synthesis of graphene layers in premixed hydrocarbon flames on a nickel catalyst substrate under various conditions.

\section{Experimental}

The synthesis layered graphene layers was performed in the premixed flame-propane and butane-oxygen mixture at atmospheric pressure, with the addition of argon. Argon was fed in an amount of 150, 250, 350, 450 and 500

${ }^{*}$ Corresponding author. $\mathrm{cm}^{3} / \mathrm{min}$.

The substrate used a nickel plate of thickness of 0.2 $\mathrm{mm}$, which was placed in the center of the burner flame. For more output graphene, the plate is rolled up into a cylinder. Between the edges of the plate, rolled into a cylinder, leaving the gap size of $2-3 \mathrm{~mm}$, which creates the conditions for the formation of gross graphene and on the inner surface of the cylinder. Photography generic flames arranged there in a substrate catalyst are shown in Figure 1.

The residence time in the flame of the plate was 5 minutes. Flame temperature depends largely on the amount of feed argon and the ratio $\mathrm{C} / \mathrm{O}$. Due to the fact that placing the substrate in its flame temperature is reduced to $30^{\circ} \mathrm{C}-50^{\circ} \mathrm{C}$ due to the heat dissipation plate and the holder, the initial flame temperature exhibited within $950^{\circ} \mathrm{C}-970^{\circ} \mathrm{C}$.

The flame temperature in the catalytic synthesis of graphene on a substrate maintained within $900^{\circ} \mathrm{C}-920^{\circ} \mathrm{C}$. Study of the formation of layered graphene layers performed at a constant flow rate of propane or butane-219 $\mathrm{cm}^{3} / \mathrm{min}$. In order to obtain the desired ratios $\mathrm{C} / \mathrm{O}$ unchanged oxygen consumption, the values of which are given in Table 1.

The study produced by the catalytic substrate particulate soot of structures was performed on Raman spectrometer NTEGRA Spectra at a wavelength $\lambda=473 \mathrm{~nm}$. The presence of graphene layers was evaluated by the presence of three characteristic peaks have: a first peak D 


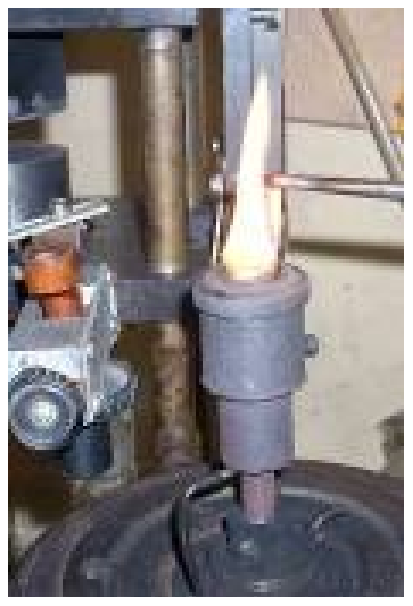

(a)

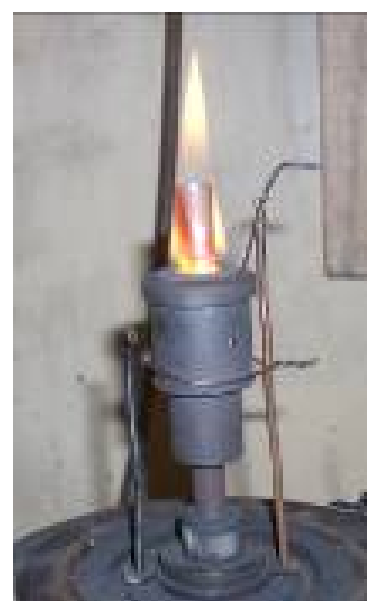

(b)
Figure 1. The photo of flames with a catalyst substrate: (a) plate, (b) cylinder.

Table 1. The flow rate of oxygen depends on the type of fuel to obtain the desired ratio $\mathrm{C} / \mathrm{O}$.

\begin{tabular}{lcccc}
\hline The value of $\mathrm{C} / \mathrm{O}$ & 0.75 & 0.85 & 0.95 & 1.05 \\
\hline $\begin{array}{l}\text { Consumption of } \mathrm{O}_{2} \\
\text { for } \mathrm{C}_{3} \mathrm{H}_{8}, \mathrm{~cm}^{3} / \mathrm{min}\end{array}$ & 438.2 & 386.6 & 345.9 & 313.0 \\
$\begin{array}{l}\text { Consumption of } \mathrm{O}_{2} \\
\text { for } \mathrm{C}_{4} \mathrm{H}_{10}, \mathrm{~cm}^{3} / \mathrm{min}\end{array}$ & 584.3 & 515.5 & 461.3 & 417.3 \\
\hline
\end{tabular}

at $1351 \mathrm{~cm}^{-1}$, G second peak at $1580 \mathrm{~cm}^{-1}$ and 2D third peak at $2700 \mathrm{~cm}^{-1}$. The ratio between the intensity of the G peak $\left(I_{G}\right)$ and $2 \mathrm{D}$ peak $\left(\mathrm{I}_{2 \mathrm{D}}\right)$ gives an estimate of the number of layers $\left(\mathrm{I}_{\mathrm{G}} / \mathrm{I}_{2 \mathrm{D}}\right)$. For a mono-layer of graphene and this ratio is less than unity. Raman spectroscopy has allowed to establish the presence of layered graphene films, as well as to evaluate the quality of the graphene layers.

\section{Results}

The experimental results in the synthesis of the graphene layers of the premixed combustion of propane and butane-oxygen mixtures at various ratios of $\mathrm{C} / \mathrm{O}$ are shown below. Argon consumption in all experiments was constant and equal to $250 \mathrm{~cm}^{3} / \mathrm{min}$. The Results obtained minimum ratio IG/I2D, characterize the amount of graphene layers on the substrate depending on the fuel source and the ratio $\mathrm{C} / \mathrm{O}$, are given in Table 2 .

It is stated that preferably in the flame of propane and butane is observed under these conditions the formation of graphene layers in an amount of 5 - 10 layers. The results of Raman spectroscopic studies of soot samples are shown in Figures $\mathbf{2}$ and $\mathbf{3}$.

It is found that the graphene layers are formed independently of the type of fuel in the studied range of ratios $\mathrm{C} / \mathrm{O}$ with a pronounced peak of graphite $\mathrm{G}$. The tendency for increasing the degree of disorder of the graphene lay- ers with increasing ratio of $\mathrm{C} / \mathrm{O}$, which is characterized by an increase in the peak intensity D. For propaneoxygen mixture degree of disorder is observed at a higher ratio of $\mathrm{C} / \mathrm{O}$ than for butane-oxygen mixture. However, butane-oxygen mixture at a ratio of $\mathrm{C} / \mathrm{O}=0.95$ was obtained the minimum number of graphene layers (three layers, $\mathrm{I}_{\mathrm{G}} / \mathrm{I}_{2 \mathrm{D}}=1.3$, Table 2).

It was studied the effect of argon flow on the synthesis of graphene layers in its submission to the propane or butane-oxygen flames. Feed argon flame affects its temperature. There is a process of lowering the temperature of the flame adjustment to the values of $950^{\circ} \mathrm{C}-970^{\circ} \mathrm{C}$, which is most favorable for the synthesis of graphene layers. It was necessary to determine the flow rate of argon, the most favorable for the synthesis of graphene at different combustion conditions.

It is found that when the ratio of $\mathrm{C} / \mathrm{O}=0.75$ for propane-oxygen flame increases in argon from $150 \mathrm{~cm}^{3} / \mathrm{min}$ to $500 \mathrm{~cm}^{3} / \mathrm{min}$ not activate the process of the formation of graphene layers, and leads to the formation of predominantly amorphous soot structure. However, the argon flow rate $150 \mathrm{~cm}^{3} / \mathrm{min}$ there is a clear graphitized structure that is characterized by the presence of three peaks characteristic of the graphene layers, Figure 4.

The research for propane-oxygen flame at a ratio of $\mathrm{C} / \mathrm{O}=1.05$ at different flow rates of argon showed the presence of layers of graphene, but with the presence of disorder, which is characterized by a peak of $\mathrm{D}$ greater intensity. When the ratio of $\mathrm{C} / \mathrm{O}=1.05$ with filing 150 $\mathrm{cm} 3 / \mathrm{min}$ argon on nickel substrate in propane-oxygen flame is observed the formation of a minimum number of graphene layers (three layers- $\mathrm{I}_{\mathrm{G}} / \mathrm{I}_{2 \mathrm{D}}=1.3$ ).

For butane-oxygen flame at $\mathrm{C} / \mathrm{O}=0.75$ increase in argon does not lead to the formation of a particulate amorphous structure. With increasing argon flow rate at $\mathrm{C} / \mathrm{O}=0.75$ in butane-oxygen flame is observed the formation of graphene layers, and even a minimal amount of Figure 5 (три слоя- $\mathrm{I}_{\mathrm{G}} / \mathrm{I}_{2 \mathrm{D}}=1.3$ ).

As a result, studies have found that as the ratio of $\mathrm{C} / \mathrm{O}$ trend increases in the degree of disorder of graphene layers, which is characterized by an increase in the peak intensity D. For propane-oxygen mixture degree of disorder is observed at a higher ratio of $\mathrm{C} / \mathrm{O}$ than for butaneoxygen mixture. It is shown that the formation of graphene layers, the optimal value is the ratio of $\mathrm{C} / \mathrm{O}=0.85$ - 0.9 and the flow of argon in the amount of $150-250$ $\mathrm{cm}^{3} / \mathrm{min}$.

Table 2. The minimum ratio $I_{G} / I_{2 D}$ depending on the ratio of $\mathrm{C} / \mathrm{O}$ and type of fuel.

\begin{tabular}{ccccc}
\hline The value of the ratio, C/O & 0.75 & 0.85 & 0.95 & 1.05 \\
\hline Propane, $\mathrm{I}_{\mathrm{G}} / \mathrm{I}_{2 \mathrm{D}}$ & 2.2 & 1.8 & 1.5 & 1.9 \\
Butane, $\mathrm{I}_{\mathrm{G}} / \mathrm{I}_{2 \mathrm{D}}$ & 1.5 & 2.0 & 1.3 & 1.6 \\
\hline
\end{tabular}




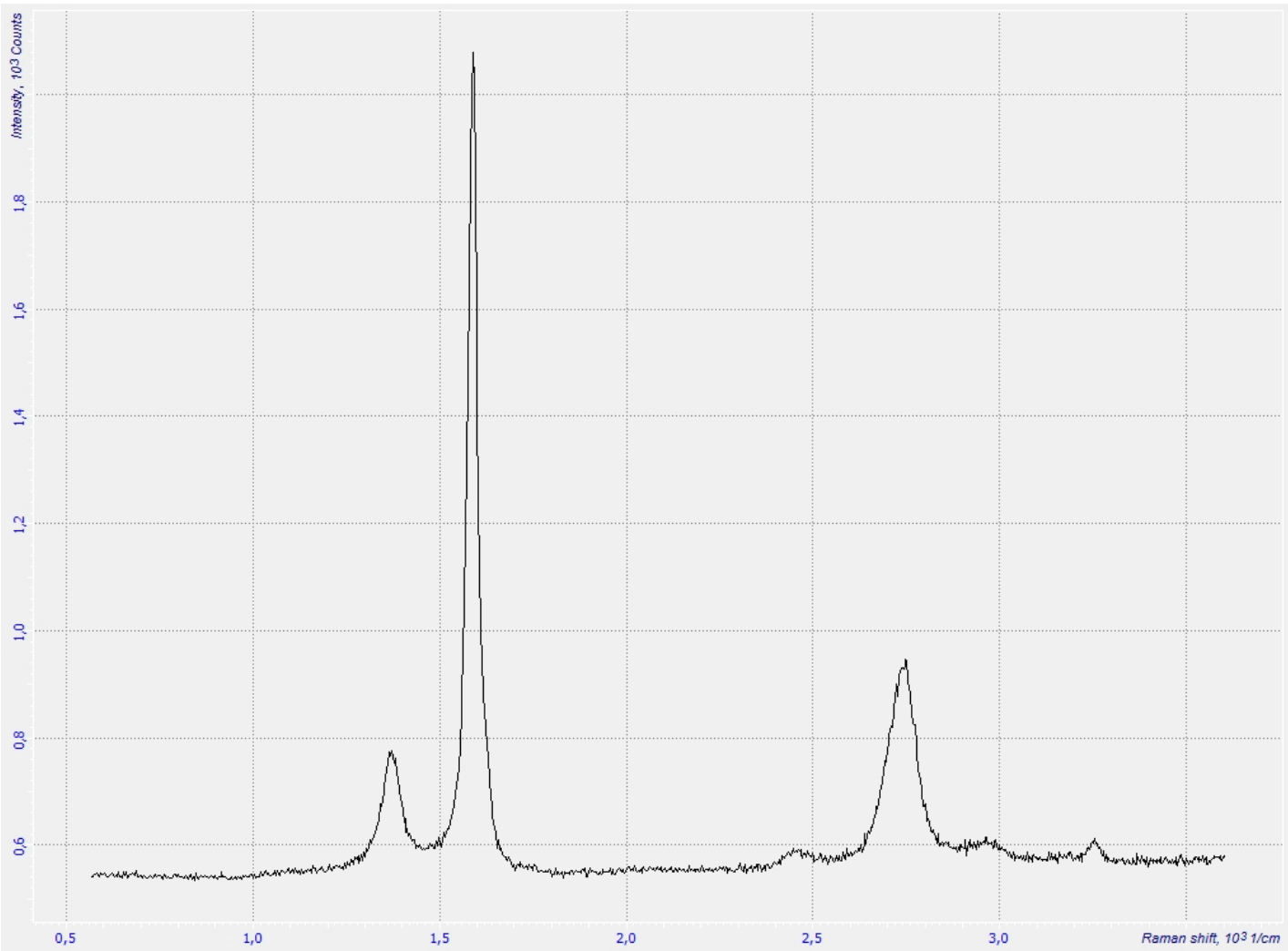

(a)

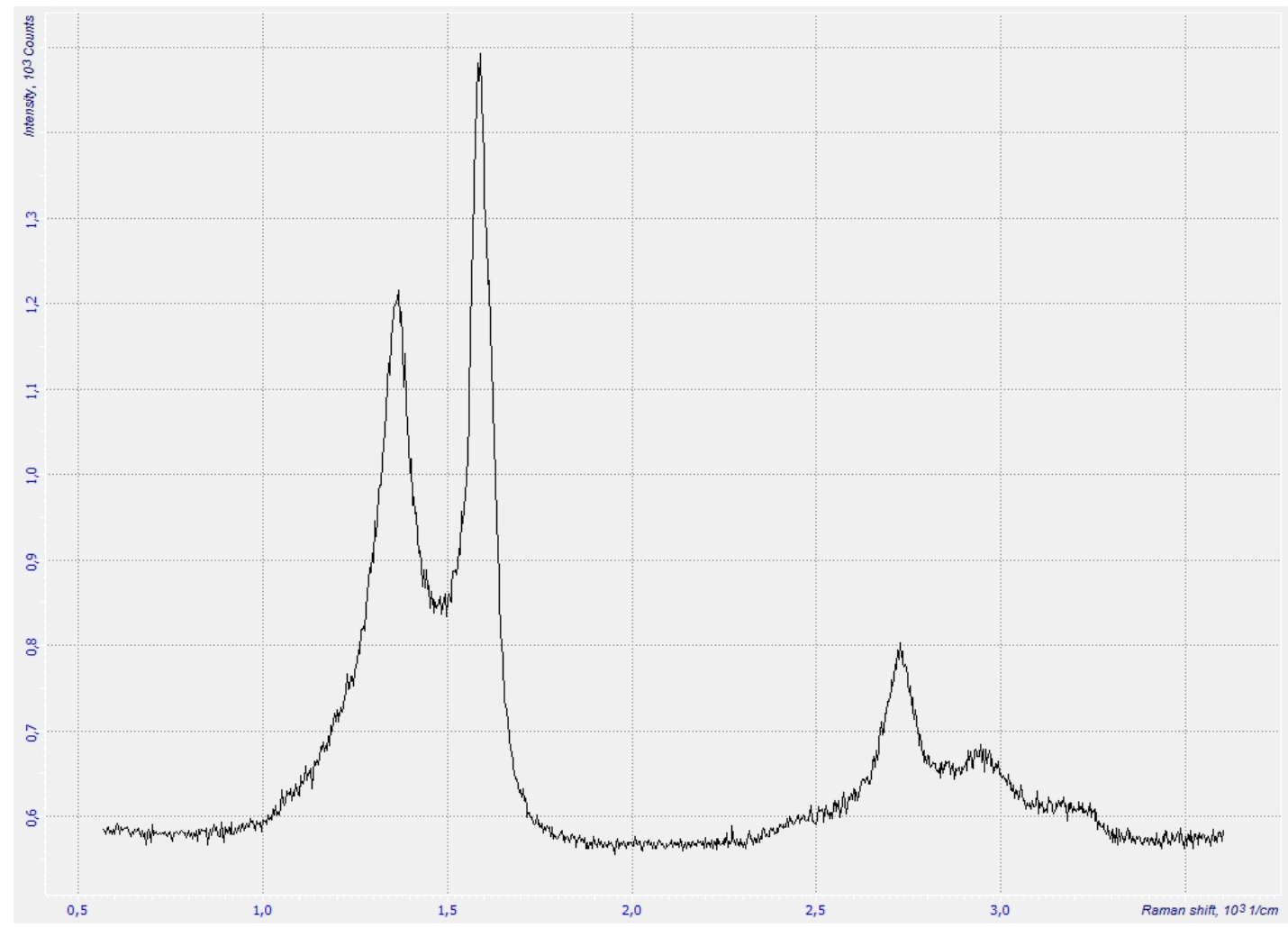

(b)

Figure 2. Raman spectra of graphene layers on a nickel substrate obtained in propane-oxygen-argon flame at values of $\mathrm{C} / \mathrm{O}$ : (a) $\mathrm{C} / \mathrm{O}=0.75\left(\mathrm{I}_{\mathrm{G}} / \mathrm{I}_{2 \mathrm{D}}=2.2\right)$; (b) $\mathrm{C} / \mathrm{O}=1.05\left(\mathrm{I}_{\mathrm{G}} / \mathrm{I}_{2 \mathrm{D}}=1.9\right)$. 


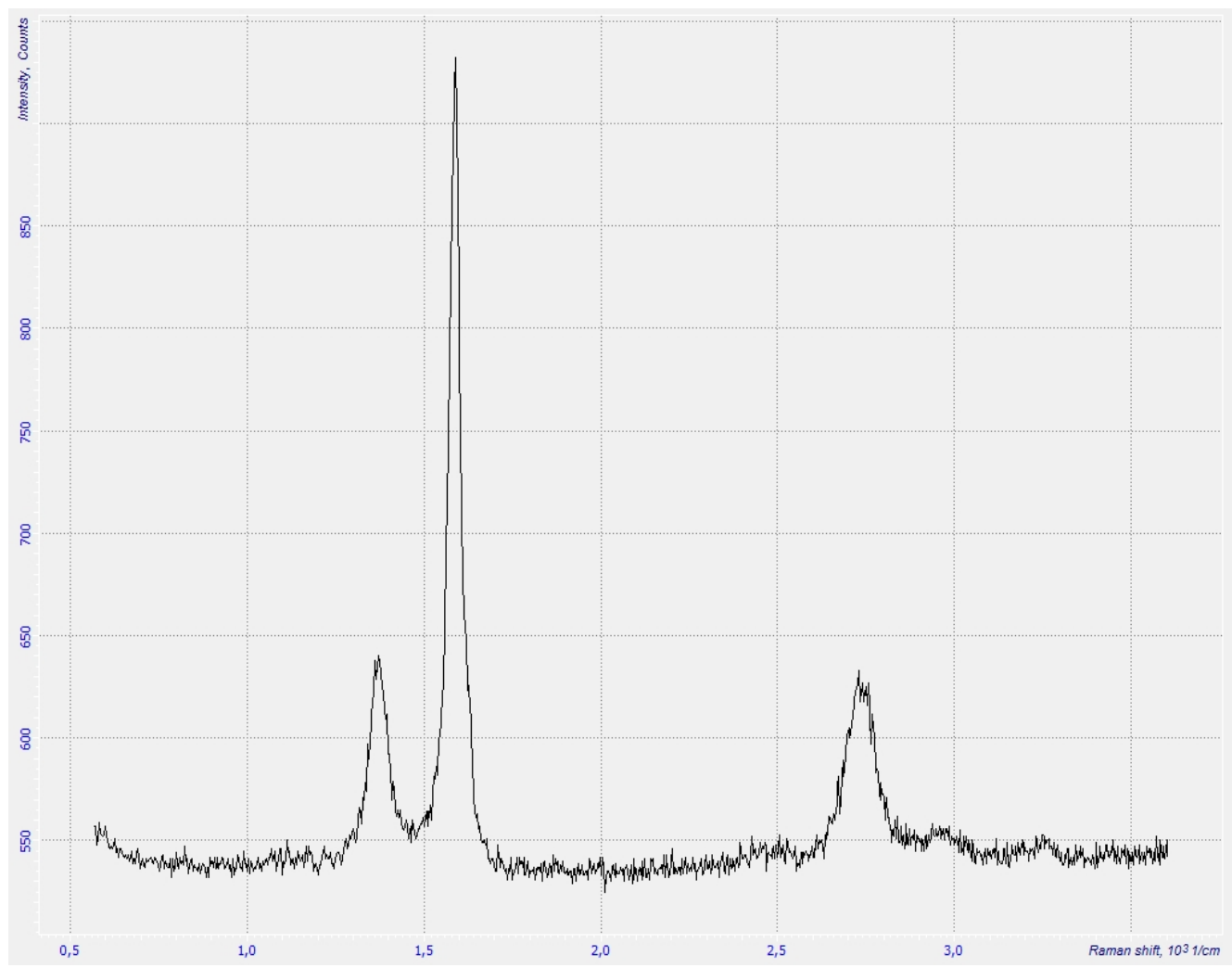

(a)

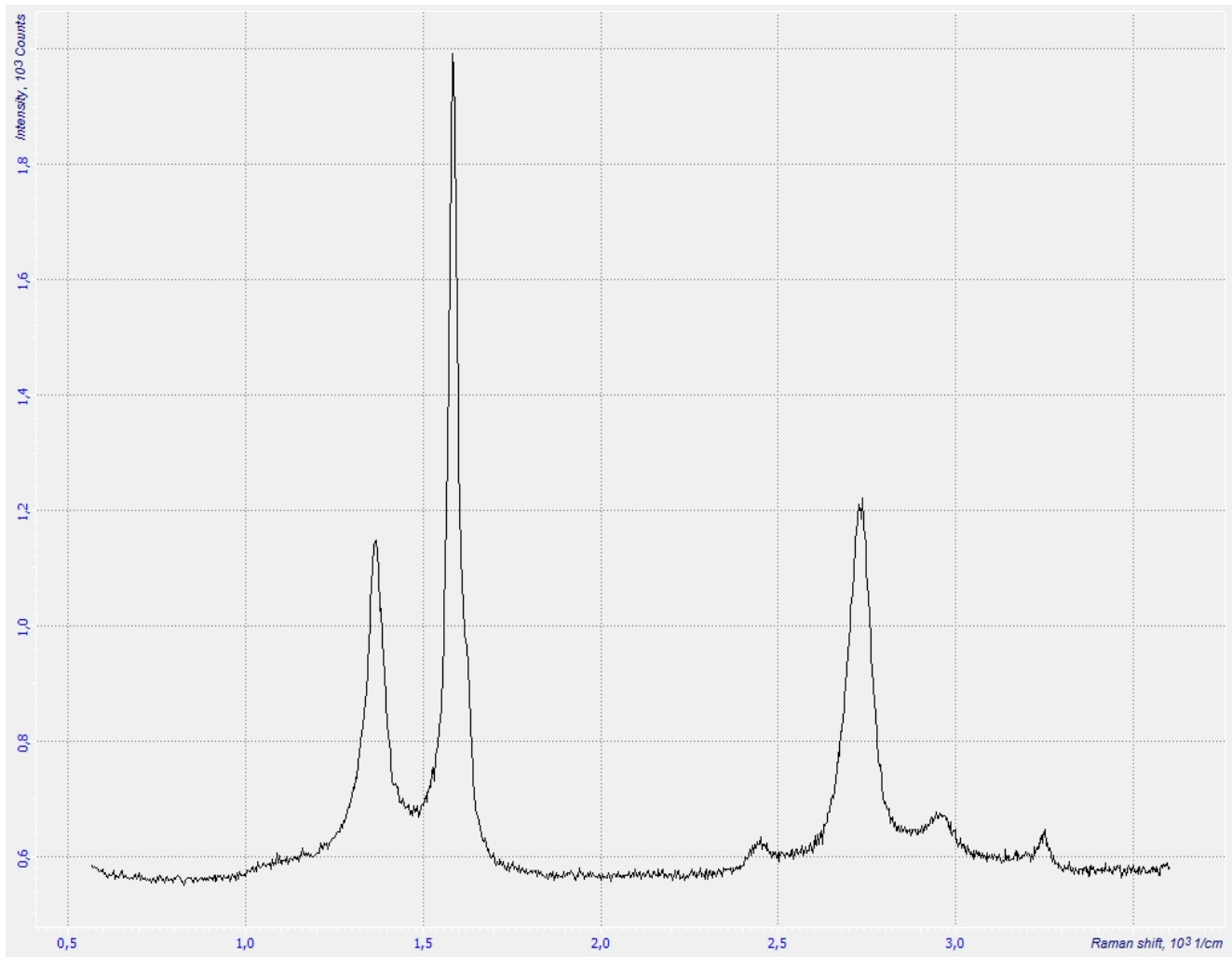

(b)

Figure 3. Raman spectra of graphene layers on a nickel substrate obtained in the butane-oxygen-argon flame at values of $\mathrm{C} / \mathrm{O}$ : (a) $\mathrm{C} / \mathrm{O}=0.75\left(\mathrm{I}_{\mathrm{G}} / \mathrm{I}_{2 \mathrm{D}}=1.5\right)$; (b) $\mathrm{C} / \mathrm{O}=1.05\left(\mathrm{I}_{\mathrm{G}} / \mathrm{I}_{2 \mathrm{D}}=1.6\right)$. 


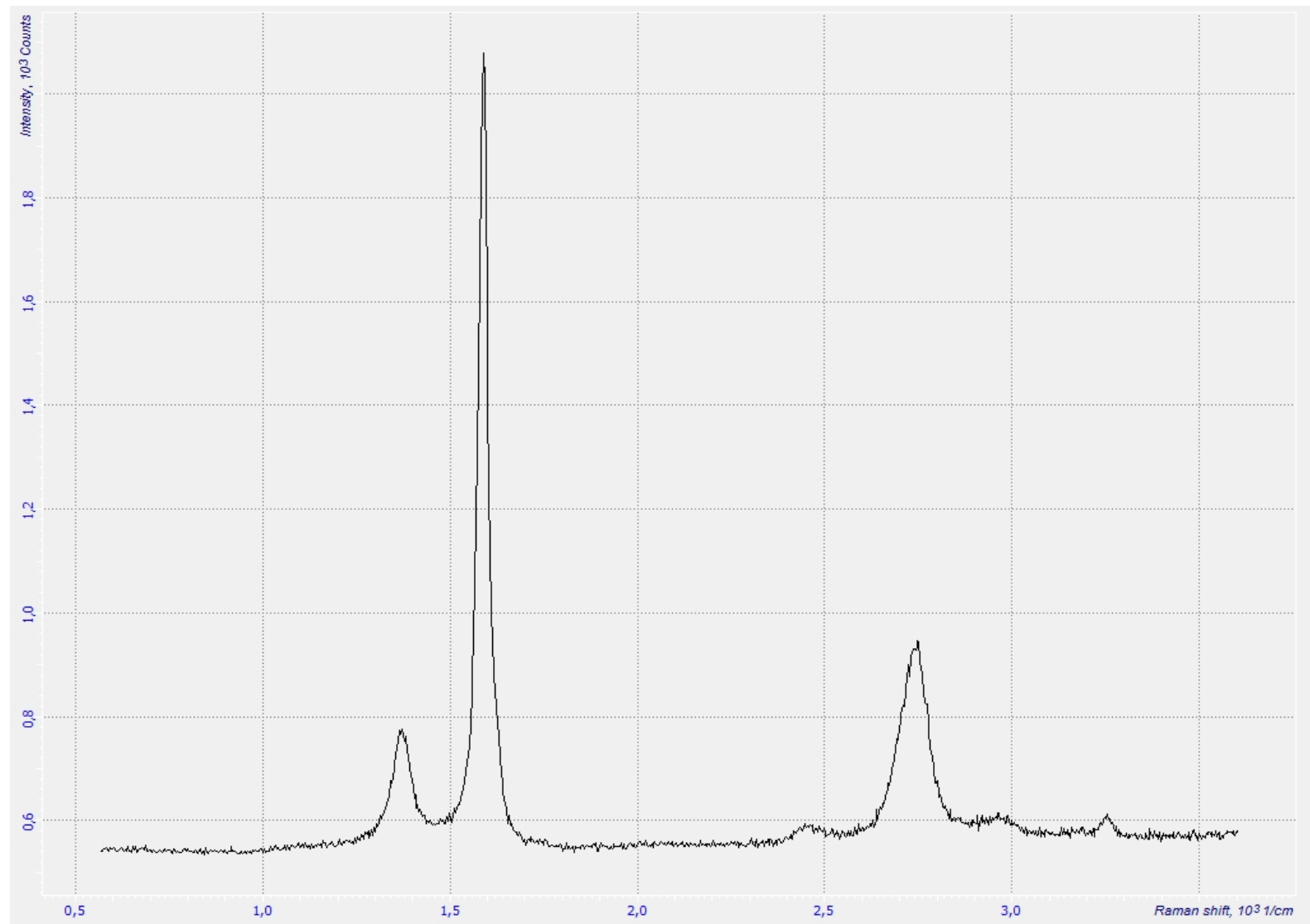

Figure 4. Raman spectrum of graphene layers: $\mathrm{Ni}, \mathrm{C}_{3} \mathrm{H}_{8} / \mathrm{O}_{2} / \mathrm{Ar}, \mathrm{C} / \mathrm{O}=0.75$, the flow of $\operatorname{argon} 150 \mathrm{~cm}^{3} / \mathrm{min}\left(\mathrm{I}_{\mathrm{G}} / \mathrm{I}_{2 \mathrm{D}}=2.2\right)$.

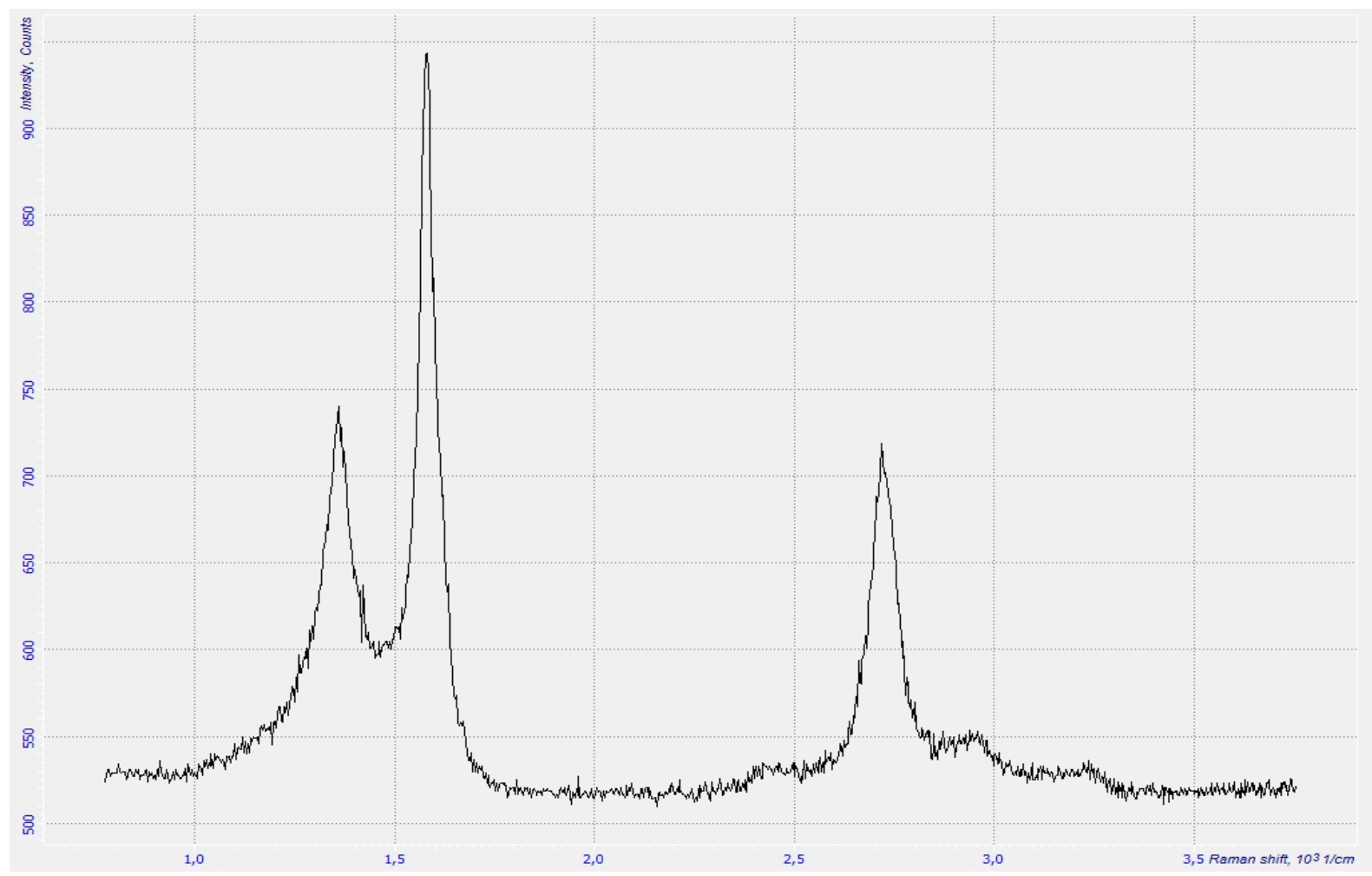

Figure 5. Raman spectrum of graphene layers: $\mathrm{Ni}, \mathrm{C}_{4} \mathrm{H}_{10} / \mathrm{O}_{2} / \mathrm{Ar}, \mathrm{C} / \mathrm{O}=0.75$, the flow of argon $500 \mathrm{~cm}^{3} / \mathrm{min}\left(\mathrm{I}_{\mathrm{G}} / \mathrm{I}_{2 \mathrm{D}}=1.3\right)$. 
The studies of the formation of layered graphene films were premixed flame in butan-argon-oxygen mixture at a pressure of 60 - 100 Torr. For this purpose, the burner as depicted in Figure 6, was placed in a quartz tube in which an initial vacuum is created 5 Torr. The experiments were performed in the following conditions: flow of butane $-200 \mathrm{~cm}^{3} / \mathrm{min}$, the flow rate of oxygen -450 $\mathrm{cm}^{3} / \mathrm{min}$, corresponding to the ratio $\mathrm{C} / \mathrm{O}=0,89$. Argon was fed in an amount of $250 \mathrm{~cm}^{3} / \mathrm{min}$. As the catalyst substrate applied plate made of copper and nickel. The flame temperature in the experiments was in the range of $900^{\circ} \mathrm{C}-950^{\circ} \mathrm{C}$. The residence time in the flame plate was 5 minutes. Photo of the burner to carry out research on the synthesis of graphene layers in the flame at low pressure is shown in Figure 6.

At the expiration of this time, the substrate deduced from the flames. Then, the system switched off, the pressure was increased to atmospheric pressure, the substrate is removed for further study. The results of studies of soot samples on Raman spectrometer are presented in Figure 7. It is found the formation of graphene layers

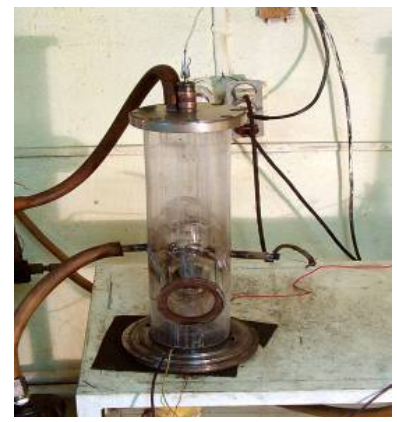

Figure 6. Photo of the burner for the synthesis of graphene layers in the flame at low pressure.

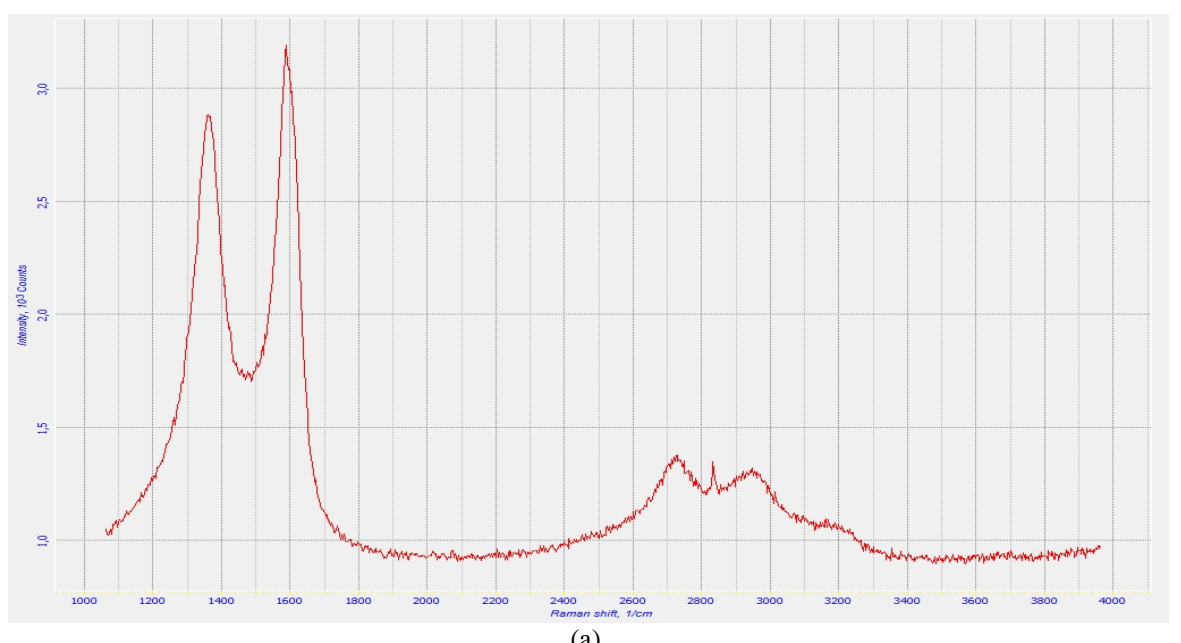

(a)

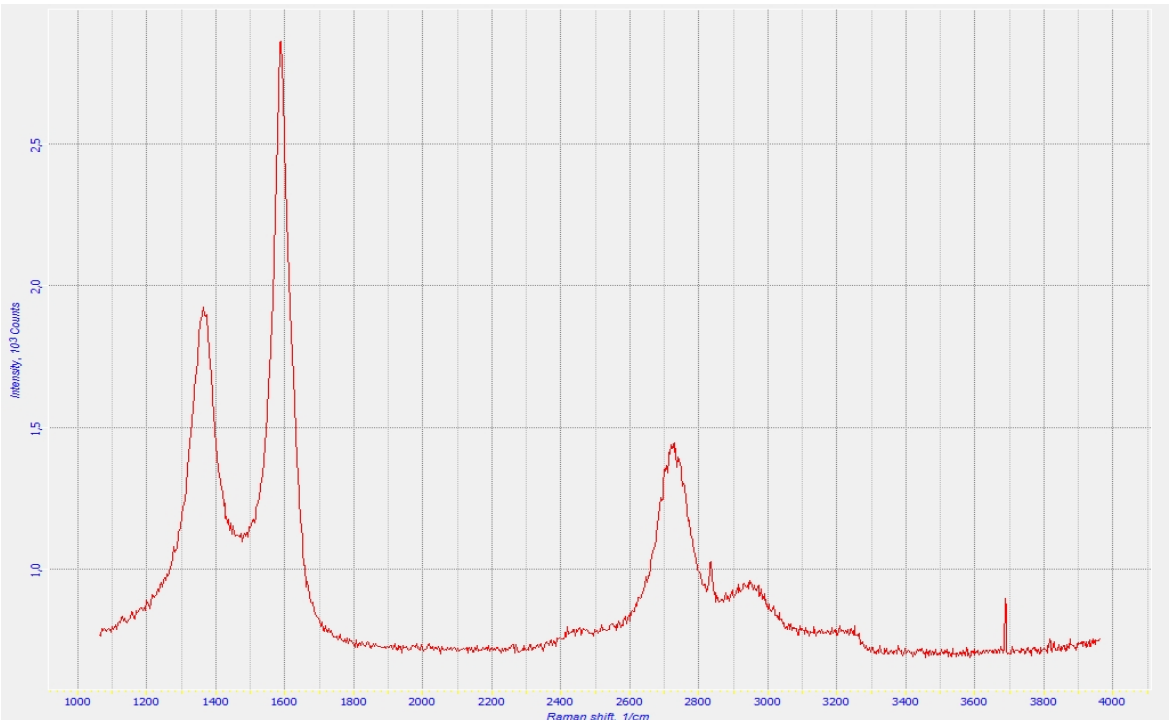

(b)

Figure 7. Raman spectra of graphene layers formed in a flame at a pressure of 80 Torr: (a) on the copper substrate, (b) on the nickel substrate. 
occurs at a low pressure as copper (Figure 7(a)), and nickel substrates (Figure 7(b)).

On a copper substrate at the given experimental conditions produced graphene layers, characterized by peaks D (1354 $\left.\mathrm{cm}^{-1}\right), \mathrm{G}\left(1587 \mathrm{~cm}^{-1}\right)$ and 2D $\left(2711 \mathrm{~cm}^{-1}\right)$, Figure 7(a). Attitude $I_{G} / I_{2 D}=3192 / 1360=2.4$ characterized by the presence of more than two substrate layers graphene. On a nickel substrate formed graphene layers, characterized by peaks D (1354 $\left.\mathrm{cm}^{-1}\right), \mathrm{G}\left(1580 \mathrm{~cm}^{-1}\right)$ and 2D $\left(2700 \mathrm{~cm}^{-1}\right)$, Figure 7(b). Attitude $\mathrm{I}_{\mathrm{G}} / \mathrm{I}_{2 \mathrm{D}}=2682 / 1352=$ 2.0 characterized by the presence on the substrate more than two graphene layers.

Comparison of Raman spectra of carbon structures formed on copper and nickel substrates, shows that on a nickel substrate formation of graphene layers are more intense than on the copper substrate. It is characterized by more pronounced peaks with a smaller shift of Raman scattering (Figure 7(b)).

\section{REFERENCES}

[1] K. S. Novoselov, A. K. Geim, S. V. Morozov, et al.,
"Two-Dimensional Gas of Massless Dirac Fermions in Graphene,” Nature, Vol. 438, 2005, pp. 197-200. http://dx.doi.org/10.1038/nature04233

[2] A. K. Geim and K. S. Novoselov, “The Rise of Graphene,” Nature Materials, Vol. 6, 2007, pp. 183-191. http://dx.doi.org/10.1038/nmat1849

[3] A. Dato and M. Frenklach, "Substrate-Free Microwave Synthesis of Graphene: Experimental Conditions and Hydrocarbon Precursors”, New Journal of Physics, Vol. 12, 2010, pp. 125013-37. http://dx.doi.org/10.1088/1367-2630/12/12/125013

[4] Z. Li, H. Zhu, D. Xie, et al., "Flame Synthesis of FewLayered Graphene/Graphite Films," Chemical Communications, Vol. 47, 2011, pp. 3520-3522. http://dx.doi.org/10.1039/c0cc05139j

[5] N. K. Memon, S. D. Tse, J. Fet. Al-Sharab, et al., "Flame Synthesis of Graphene Films in Open Environments," Carbon, Vol. 49, 2011, pp. 5064-5070. http://dx.doi.org/10.1016/j.carbon.2011.07.024 